\title{
Clinical benefits of vitamin A supplementation in infants and children with severe pneumonia
}

\author{
Prisca T., J. S. Lisal, Azis Tanra, Dasril Daud
}

\begin{abstract}
Background About 190 million preschool children living in developing countries are at risk of vitamin A deficiency. Vitamin A deficiency and acute respiratory tract infection (ARI) are public health problems in developing countries. Children with vitamin A deficiency are more susceptible to measles, respiratory tract infection, and other infections. Some studies show that vitamin A supplements may reduce the severity of respiratory tract infection and other systemic complications of measles, and diarrhea.

Objective To evaluate the effect of vitamin A supplementation in infants and children with severe pneumonia.

Methods The study was a randomized trial on children with severe pneumonia. Participants were randomly assigned to either receive vitamin $\mathrm{A}$ in addition to standard treatment (Group A), or standard treatment alone (Group C). Time to achieve the normal respiratory rate, time to achieve disappearance of subcostal retractions and fine rales were compared between the 2 groups. Result There was no significant difference in the achievement of normal respiratory rate between the vitamin group and the control group (3.08 days vs 3.29 days). There was also no significant difference in the disappearance of subcostal retractions among the two groups (2.30 days vs 2.48 days). However, there was significant difference in the disappearance of fine rales between the two groups. The disappearance of fine rales in the vitamin A group occurred earlier (mean 3.72 days) than in the control group (mean 4.04 days) $(\mathrm{P}<0.01)$.

Conclusions This study indicates that no significant difference in the achievement of normal respiratory rate and disappearance of subcostal retractions between the vitamin A group as compared to the control group, but there was a significant difference in the disappearance of fine rales between two groups. [Paediatr Indones 2007;47:120-123].
\end{abstract}

Keywords: vitamin A supplementation, severe pneumonia, pediatrics
$\mathrm{V}$ itamin A deficiency and acute respiratory tract infection (ARI) are public health problems in developing countries. ${ }^{1}$ Children with vitamin A deficiency are more susceptible to measles, respiratory tract infection, and other infections, ${ }^{2}$ that may increase the morbidity and mortality rates. ${ }^{3}$ Vitamin A is very important for immunocompetence patients. ${ }^{4}$ Vitamin $\mathrm{A}$ in the body acts within the nucleus to regulate cell differentiation through gene transcription, therefore affecting a number of processes in the body, such as for cell changing, immunity function, and increasing body defense against infection. A person suffering from vitamin A deficiency will experience many cellular and humoral immunity functional disorders, keratinization of epithelial respiratory tract, and reduction in mucous secretion. Therefore, it causes deteriorating in body defense mechanism against infection. 5,6 Barclay et al ${ }^{7}$ reported that vitamin $\mathrm{A}$ is used therapeutically for pediatric measles with a minimum dosage of 400,000 IU for children and 200,000 IU for infants. Moreover, it reduces case fatality rate, severity of illness and duration of pneumonia in measles complicated with pneumonia.

From The Department of Child Health, Medical School, Hasanuddin University, Makassar, Indonesia.

Reprint requests to: Prisca T, MD, Department of Child Health, Medical School, Hasanuddin University, Wahidin Sudirohusodo Hospital, Makassar, Indonesia. Tel/Fax. 62-411-590738. 
The relation of vitamin $A$ and non-measles pneumonia is still controversial. A randomized controlled clinical trial in Peru reported that vitamin A supplementation increased the severity of pneumonia. ${ }^{8}$ This study aimed to evaluate the clinical benefits of vitamin A supplementation given with standard therapy in infants and children.

\section{Methods}

A randomized controlled trial with was conducted from September 1, 2005 to January 15, 2006. Children aged 6 months to 5 years hospitalized in the pediatric ward of Wahidin Sudirohusodo Hospital and Labuang Baji Hospital, Makassar, due to severe pneumonia were included in this study. We included severe pneumonia patients aged 6 months -5 years old. We excluded children with non-infectious pneumonia, those with poor nutritional status receiving high dose of vitamin $\mathrm{A}$ in the past 4 months, children who have received antimicrobial therapy before hospital admission, bronchial asthma, xerophthalmia, or acquired heart disease. Each patient was randomly assigned to either standard treatment plus vitamin A (Group A) or standard treatment plus placebo (Group C). Data collected included age, sex, body weight, cough, respiratory rate, subcostal retractions, cyanosis and the presence of fine rales.

Participants in Group A received vitamin A added in $2 \mathrm{ml}$ orange syrup, and dropped with a pipette. The dosage of vitamin $\mathrm{A}$ was adjusted to age; children aged 6 months-1 year were given 100,000 IU and children above 1 year old were given 200,000 IU. Vitamin A was given once during admission after the diagnosis was confirmed. The control group was given orange syrup $2 \mathrm{ml}$ dropped into the mouth once during hospital admission. All patients were assessed for their respiratory rate, subcostal retractions, and fine rales everyday. Data were analyzed with chi-square and MannWhitney test with $\mathrm{P}$ value of $<0.05$ was considered significant.

\section{Results}

Ninety eight subjects were enrolled, comprising 50 children in Group A (vitamin A supplemented) and 48 children in Group C. Table 1 shows the baseline characteristics of the participants in both groups; no important differences were noted.

Table 2 shows that there was no significant difference in the achievement of normal respiratory rate between two groups. Table 3 shows that there was no significant difference in the disappearance of subcostal retractions among the two groups $(\mathrm{P}>0.05)$. Table 4 shows that there was a significant difference in the disappearance of fine rales between the two groups, with the mean value of 3.7 days vs 4.0 days $(\mathrm{P}<0.01)$.

\section{Discussion}

One hundred subjects with pneumonia fulfilled the criteria; however, 2 subjects dropped out during study

Table 1. Baseline characteristics of the participants in both groups

\begin{tabular}{|c|c|c|}
\hline & $\begin{array}{c}\text { Vitamin A } \\
\mathrm{n}=50\end{array}$ & $\begin{array}{c}\text { Control } \\
n=48\end{array}$ \\
\hline \multicolumn{3}{|l|}{ Age } \\
\hline Mean (years) & 1.86 & 1.96 \\
\hline \multicolumn{3}{|l|}{ Sex } \\
\hline Male, \% & 44 & 58 \\
\hline Female, \% & 56 & 42 \\
\hline \multicolumn{3}{|l|}{ Nutritional status } \\
\hline Well nourished, \% & 64 & 60 \\
\hline Under nourished, \% & 36 & 40 \\
\hline \multicolumn{3}{|l|}{ Temperature } \\
\hline Mean $\left({ }^{\circ} \mathrm{C}\right)$ & 38.5 & 38.3 \\
\hline
\end{tabular}

Table 2. Time to achieve normal respiratory rate among two groups

\begin{tabular}{lcc}
\hline $\begin{array}{l}\text { The achievement of normal- } \\
\text { respiratory rate (days) }\end{array}$ & $\mathrm{A}$ & Groups \\
& $\mathrm{n}=50$ & $\mathrm{C}$ \\
Mean & 3.1 & $\mathrm{n}=48$ \\
Median & 3.0 & 3.3 \\
SD & 0.92 & 3.0 \\
Range & $1-5$ & 0.77 \\
Mann- Whitney test & $\mathrm{z}=1.218$ & $\mathrm{P}=0.233$
\end{tabular}

Table 3. Duration of disappearance of subcostal retractions among two groups

\begin{tabular}{lcc}
\hline $\begin{array}{l}\text { The duration of disappearance- } \\
\text { of subcostal retractions (days) }\end{array}$ & $\mathrm{A}$ & Groups \\
& $\mathrm{n}=50$ & $\mathrm{C}$ \\
\hline Mean & 2.3 & 2.5 \\
Median & 2.0 & 2.0 \\
SD & 0.5 & 0.6 \\
Range & $1-3$ & $1-4$ \\
\hline Mann- Whitney test & $\mathrm{z}=-1.601$ & $\mathrm{P}=0.109$
\end{tabular}


Prisca T et al: Vitamin A supplementation in severe pneumonia

Table 4. Duration of disappearance of fine rales between the two groups

\begin{tabular}{lcc}
\hline $\begin{array}{l}\text { The duration of disappearance- } \\
\text { of fine rales (days) }\end{array}$ & $\begin{array}{c}\text { Groups } \\
\mathrm{n}=50\end{array}$ & $\mathrm{C}$ \\
& 3.7 & 4.0 \\
Mean & 4.0 & 4.0 \\
Median & 0.57 & 0.54 \\
SD & $3-5$ & $3-5$ \\
Range
\end{tabular}

Mann- Whitney test $\quad z=-2.769 \quad P=0.006$

period in C group, 1 refused being hospitalized on the $5^{\text {th }}$ days of treatment, and 1 subject passed away on the $2^{\text {nd }}$ day of hospitalization. Therefore, a total of 98 subjects were included in the study, comprising of 50 children in the vitamin A supplemented group (A) and 48 children in the control group (C).

The baseline characteristics of the participants were comparable (Table 1). Barclay et al ${ }^{7}$ reported that there was no significant differences between vitamin A group and control group in terms of age, nutritional state, duration of illness, prevalence of complications, and serum vitamin A concentration, but the mortality rate was twice as high as in the control group.

The achievement of normal respiratory rate did not differ between the two groups, i.e., 3.1 days in Group A and 3.3 days in Group C; this was similar to the study of Fawzi et al. ${ }^{1}$ On the contrary, a study in Santiago Chile showed that vitamin A supplementation gave more rapid resolution of tachypnea for children with severe hypoxemia caused by RSV. ${ }^{9}$ Study in Vietnam ${ }^{10}$ reported that there was no significant difference among the two groups in terms of duration of hospitalization, achievement of normal respiratory rate, and normalization of fever. However, shorter hospitalization (6.7 days) was experienced in the moderately malnourished vitamin Asupplemented group compared to the control group (8.6 days) $(\mathrm{P}=0.04)$.

There was also no significant difference in the duration of disappearance of subcostal retractions between the two groups with a mean value in group $\mathrm{A}$ and group $\mathrm{C}$ were 2.3 days and 2.5 days, respectively $(\mathrm{P}=0.109)$. Stephensen et $a^{8}$ in the placebocontrolled clinical trial in children aged 3 months -10 years old with pneumonia reported that the prevalence rates of retraction and the requirement for supplemental oxygen was even lower in the placebo group than that in the vitamin A group.
There was a statistically significant difference in the duration of disappearance of fine rales between the two groups, although clinically the difference was marginal (3.7 days in Group A vs. 4.0 days in Group C). It means that clinical benefits of vitamin A supplement on severe pneumonia in infants and children is questionable. Vitamin A is important in promoting normal respiratory epithelial differentiation and growth, as well as anti-inflammation. The role of vitamin $\mathrm{A}$ in preventing inflammation is related to its interaction with leucocytes, particularly neutrophyls, since vitamin A reduces neutrophyl superoxide production, ${ }^{5}$ one of the causes of respiratory tract inflammation.

We conclude that the addition of vitamin A to standard treatment in infants and children with severe pneumonia does not affect the achievement of normal respiratory rate and disappearance of subcostal retractions, but marginally fasten the disappearance of fine rales.

\section{References}

1. Fawzi WW, Mbise RL, Fataki MR, Herrera MG, Kawau F, Hertzmark E, et al. Vitamin A supplementation and severity of pneumonia in children admitted to the hospital in Dar es Salaam, Tanzania. Am J Clin Nutr 1998;68:187-92.

2. ARI News. In: Vitamin A. 1990; p. 1-8.

3. Munazir Z. Peran mikronutrien pada respon imun. Presented at IDAI SUL-SEL KAMAS, Makassar, 2003.

4. Combs GF. Vitamin A. In: the vitamins. San Diego New York: Academic Press; 1992. p. 121-40.

5. Reifen R. Vitamin A as an anti-inflammatory agent. Proceedings of the Nutrition Society 2002;61:397-400.

6. West KP. Preventing Vitamin A deficiency: translating science to action. In: Black RE, Michaellsen KF, editors. Nestle nutrition workshop series pediatric program. Philadelphia: Lippincott Williams \& Wilkins; 2002. p. 71.

7. Barclay AJG, Foster A, Sommer A. Vitamin A supplements and mortality related to measles: randomized clinical trial. BMJ 1987;294:294-6.

8. Stephensen CB, Franci LM, Hernandez H, Campos M, Gilman RH, Alvarez JO. Adverse effects of high dose vitamin A supplements in children hospitalized with pneumonia. Pediatrics 1998;101:e3.

9. Dowel S, Papic Z, Bresee J, Larranaga C, Mendez M, Sowell $\mathrm{AL}$, et al. Treatment of respiratory syncytial virus infection with vitamin A: a randomized placebo-controlled trial in Santiago, Chile. Pediatr Infect Dis J 1996;15:782-6. 
Prisca $\mathrm{T}$ et al: Vitamin A supplementation in severe pneumonia

10. Si NV, Grytter C, Vy NNT, Hue NB, Karup Pedersen F. High dose vitamin A supplementation in the course of pneumonia in Vietnamese children. Acta Pediatrica 1997;86:1052-5. 